\title{
Burn management during the COVID-19 pandemic: recommendations and considerations
}

\author{
Amjad Soltany, Ali Ramez Hasan¹, Farah Mohanna²
}

Department of Plastic and Reconstructive Surgery, Al Mouwasat University Hospital, Faculty of Medicine, Damascus University, Damascus, ${ }^{1}$ Faculty of Medicine, Tishreeen University, Lattakia, ${ }^{2}$ Department of Pathology, Tishreen University Hospital, Faculty of Medicine, Tishreeen University, Lattakia, Syria

\begin{tabular}{|c|}
\hline Access this article online \\
\hline Website: www.avicennajmed.com \\
\hline DOI: 10.4103/ajm.ajm_153_20 \\
\hline Quick Response Code: \\
\hline
\end{tabular}

\begin{abstract}
Coronavirus disease-2019 (COVID-19) is a respiratory disease, caused by a novel coronavirus (SARS-COV-2). This disease has been raising international public health concerns since its recent outbreak in December 2019. As the virus is easily transmitted by respiratory droplets, all hospital departments needed to change their practices in an attempt to control the spread of this virus. Burn units and clinics are particularly affected by this pandemic because of the larger risk of contamination for both patients and caregivers. Furthermore, cross-clinical aspects especially pain management and complications such as coagulopathy might be caused by both extensive burns and COVID-19 infections, which makes the management of these patients particularly challenging. That's why we covered both main aspects in this review. In addition, we present briefly a synthesis of guidelines from several entities to help manage the health crisis and provide optimal care for all burn patients during this pandemic.
\end{abstract}

Key words: Burn management, coagulopathy, coronavirus, pain management

Highlights:

- All new burn patients, including pediatric burn patients, should undergo solitary isolation for 3-5 days, 14 days is recommended if possible, for medical observation.

- Preliminary screening, which includes blood routine and chest CT examinations, is performed routinely on all newly admitted patients.

- Severe burn patients should be admitted to burn intensive care unit (BICU) and should be treated as suspects of COVID-19.

- Sputum absorption, airway lavage, and other invasive operations should be minimized as much as possible.

- For urgent surgeries, lung CT and routine blood tests must be performed right before any surgical procedure, and the COVID-19 PCR test should be performed based on clinical symptoms and epidemiology.

- Surgery is the highest risk point of COVID-19 infection exposure especially in the early treatment of burn patients.

- For patients with negative COVID-19 testing, urgent procedures have to be administrated in negative-pressure operating rooms, and healthcare staff must take proper protective precautions.
Address for correspondence: Dr. Amjad Soltany, Department of Plastic and Reconstructive Surgery, Al Mouwasat University Hospital, Faculty of Medicine, Damascus University, Damascus, Syria.

E-mail: amjad.soltany@gmail.com
This is an open access journal, and articles are distributed under the terms of the Creative Commons Attribution-NonCommercial-ShareAlike 4.0 License, which allows others to remix, tweak, and build upon the work non-commercially, as long as appropriate credit is given and the new creations are licensed under the identical terms.

For reprints contact: reprints@ medknow.com

Cite this article as: Soltany A, Hasan A, Mohanna F. Burn management during the COVID-19 pandemic: Recommendations and considerations. Avicenna J Med 2020;10:163-73. 
- Patients are advised to do an online check-in and share their status and improvement of rehabilitation.

- It is recommended to suspend the rehabilitation treatment with close contact.

- The therapeutic strategy for underlying pain management in COVID-19 burn patients remains similar to the regular burn patients; however, more attention for the opioid administration should be paid.

- Burn patients associated with COVID-19 require strict monitoring and follow-up. Routine chemical venous thromboembolism (VTE) prophylaxis should be also applied. An escalated dose VTE prophylaxis should be seriously considered as the risk of coagulopathy notably increases in such cases.

\section{INTRODUCTION}

Coronavirus disease-2019 (COVID-19) is a current international emergency; a viral pandemic with a high transmission rate. ${ }^{[1]}$ At the time of writing this article, there have been more than 7.2 million confirmed cases of COVID-19 including more than 360 thousand deaths. ${ }^{[1]}$ On another note, burns are a critical public health problem; they are the main cause of morbidity and of about 180,000 deaths annually. ${ }^{[2]}$ Therefore, multiple burn centers and health facilities have suggested management strategies for burn treatment during this pandemic. A burn is considered an acute condition associated with many systemic disorders, most notably coagulopathy ${ }^{[3]}$ which is also a major complication in COVID-19 patients. ${ }^{[4]}$ Moreover, pain experienced by burn patients can be unbearable and requires serious attention and efficient management. In this review, we discuss points of clinical concern in burn patients infected with COVID-19 with a special focus on coagulopathy and pain management.

\section{MATERIALS AND METHODS}

We have conducted a scoping review of published literature on burn management during the COVID-19 pandemic in addition to pain management and coagulopathy disorder in both burn and COVID- 19 patients.

\section{Liferature search}

A computer literature search of Google Scholar and PubMed had been done including publications from December 15, 2019, till the middle of May, 2020 by May using the following keywords: "Coronavirus," “COVID-19," "pandemic," "burn," "burn patients," "burn management," "burn strategy," "burn center," " burn experience," "pain," "pain management," "coagulopathy," "anticoagulant," "thromboembolic complications," and "analgesic agents." They were either used individually or in combination.

\section{Scope and criteria}

We included all relevant articles about management strategies for burn patients in the midst of COVID-19 pandemic; this comprises all published articles, as well as the WHO related reports, and the recommendations for management approaches for burn patients in the midst of COVID-19 pandemic released by credited health institutions and professional medical associations. Also, we included the most inclusive articles about coagulopathy and pain management in both burn patients and COVID-19 ones and discussed narratively these two topics in burn COVID-19 patients.

\section{RESULTS}

The literature search identified 196 articles. Of them, nineteen publications were eligible for this review. All published articles talking about management strategies and recommendations for burn patients in the midst of COVID-19 pandemic were included in this scoping review. Concerning the two clinical aspects (coagulopathy and pain management), we included the most inclusive articles about these two topics in both burn patients and COVID-19 ones.

These publications provide considerations and recommendations on burn management during this pandemic, covering all aspects of home treatment, hospital admission, ward preparations, pre-lduring-।postoperative recommendations, rehabilitation treatment, emotional support, the use of telemedicine in burn patients during COVID-19 pandemic, and the most notable cross-clinical aspects and complications caused by both extensive burns and COVID-19 infection. Studies were classified according to their scope, study ID, place or professional society, article type, and their recommendations. They were tabulated and discussed narratively. The summary of the included articles is shown in Table 1.

In this review, we had followed the checklist of the "Preferred Reporting Items for Systematic Reviews and Meta-Analyses Protocols (PRISMA)." ${ }^{[5]}$ The selection process is explained by the PRISMA flow diagram [Figure 1]. 
Table I: Summary of the articles included in this scoping review

\begin{tabular}{|c|c|c|c|c|}
\hline Scope & Study ID & $\begin{array}{l}\text { Place or } \\
\text { professional society }\end{array}$ & $\begin{array}{l}\text { Article type or study } \\
\text { design }\end{array}$ & Key points (results) \\
\hline \multirow[t]{2}{*}{$\begin{array}{l}\text { First aid treatment } \\
\text { for minor burns at } \\
\text { home }\end{array}$} & Barret et al. ${ }^{[6]}$ & $\begin{array}{l}\text { China, Singapore, Japan, } \\
\text { Italy, Spain, the UK, and } \\
\text { the US }\end{array}$ & $\begin{array}{l}\text { An international multicenter } \\
\text { report of strategy and } \\
\text { experience }\end{array}$ & $\begin{array}{l}\text { - Patients should stay home and avoid coming to any } \\
\text { hospital unless it is an extremely critical situation. } \\
\text { - Minor burns }<10 \% \text { total body surface area (TBSA) are } \\
\text { not routinely admitted. }\end{array}$ \\
\hline & Ma et al..$^{[7]}$ & China & $\begin{array}{l}\text { Recommendations/ } \\
\text { suggestions }\end{array}$ & $\begin{array}{l}\text { - Explaining the whole protocol for management of first aid } \\
\text { treatment for minor burns at home. }\end{array}$ \\
\hline \multirow[t]{2}{*}{$\begin{array}{l}\text { Hospital admissions } \\
\text { in general; burn } \\
\text { patient classifications } \\
\text { and ward } \\
\text { management during } \\
\text { COVID-19 pandemic }\end{array}$} & Ma et al..$^{[7]}$ & China & $\begin{array}{l}\text { Recommendations/ } \\
\text { suggestions }\end{array}$ & $\begin{array}{l}\text { - Suspected patients with new coronavirus pneumonia } \\
\text { must be immediately managed in isolation. } \\
\text { - Admit patients one by one, and no more than a } \\
\text { companion should be allowed for each patient. } \\
\text { - Preliminary screening, which includes blood routine } \\
\text { and computerized thermography (CT) examinations, is } \\
\text { performed routinely on all newly admitted patients. } \\
\text { - Patients with negative results in the preliminary screening } \\
\text { can be hospitalized whereas those with lymphocyte } \\
\text { number decline and/or exudative inflammation shown by } \\
\text { chest CT must go to the fever clinics. }\end{array}$ \\
\hline & Li et al. ${ }^{[8]}$ & China & $\begin{array}{l}\text { Recommendations/ } \\
\text { suggestions }\end{array}$ & $\begin{array}{l}\text { - Only one caregiver is permitted to escort each mature } \\
\text { patient and only two caregivers for pediatric ones. } \\
\text { - Changing the caregiver shall not be permitted. }\end{array}$ \\
\hline \multirow[t]{2}{*}{ Ward preparations } & Ma et al. ${ }^{[7]}$ & China & $\begin{array}{l}\text { Recommendations/ } \\
\text { suggestions }\end{array}$ & $\begin{array}{l}\text { - Every new burn patient in this space should undergo } \\
\text { solitary isolation for at least 3-5 days for medical } \\
\text { observation. } \\
\text { - Patients can be accommodated if they do not present any } \\
\text { symptoms of COVID-19 after } 2 \text { weeks. }\end{array}$ \\
\hline & Barret et al. ${ }^{[6]}$ & $\begin{array}{l}\text { China, Singapore, Japan, } \\
\text { Italy, Spain, the UK, and } \\
\text { the US }\end{array}$ & $\begin{array}{l}\text { An international multicenter } \\
\text { report of strategy and } \\
\text { experience. }\end{array}$ & $\begin{array}{l}\text { - Severe burn patients should be admitted to the burn } \\
\text { intensive care unit (BICU) and treated as COVID-19 } \\
\text { suspects. } \\
\text { - Wards should be divided into a clean area, a potentially } \\
\text { infected area and an infected area with instructive lines. } \\
\text { - Public spaces in the ward shall be available only for } \\
\text { patients who have been admitted to the hospital for more } \\
\text { than } 2 \text { weeks. }\end{array}$ \\
\hline \multirow[t]{2}{*}{$\begin{array}{l}\text { Management of } \\
\text { major burns: Medical } \\
\text { history taking, and } \\
\text { fever as a frequent } \\
\text { clinical symptom of } \\
\text { COVID-19 and burns }\end{array}$} & Huang et al. ${ }^{[9]}$ & China & A literature review. & $\begin{array}{l}\text { - Ask whether the patient had been to any infected area in } \\
\text { the past } 2 \text { weeks, then take the medical history related to } \\
\text { the burn. }\end{array}$ \\
\hline & Ma et al. ${ }^{[7]}$ & China & $\begin{array}{l}\text { Recommendations/ } \\
\text { suggestions }\end{array}$ & $\begin{array}{l}\text { - Try to approach determining the cause of fever by a } \\
\text { detailed inquiry about the history related to exposure to } \\
\text { the infection along with chest CT and routine blood tests. } \\
\text { Major burns that cause fever have some distinctive } \\
\text { features such as wide area burns, wounds with } \\
\text { substantial exudate, or following major surgeries. } \\
\text { - Fever related to burn wounds is not accompanied by } \\
\text { coughing except for cases associated with inhalation } \\
\text { injuries. }\end{array}$ \\
\hline \multirow[t]{2}{*}{$\begin{array}{l}\text { Dressing changes for } \\
\text { burns }\end{array}$} & Ma et al. ${ }^{[7]}$ & China & $\begin{array}{l}\text { Recommendations/ } \\
\text { suggestions }\end{array}$ & $\begin{array}{l}\text { - If there is a possible infectious exposure during wound } \\
\text { examination and dressing change, instantly flush with } \\
\text { water and disinfect any area that might be infected with } \\
75 \% \text { ethanol or chlorine disinfectant. } \\
\text { - Extend the interval between dressing changes depending } \\
\text { on the exudate and the progress of the wound up to } \\
2-3 \text { days. }\end{array}$ \\
\hline & Wang et al. ${ }^{[10]}$ & China & A letter to the editor & $\begin{array}{l}\text { - Take advantage of modern dressing such as foam dressing } \\
\text { and negative pressure wound therapy (vacuum assisted } \\
\text { closure) to prolong the intervals. }\end{array}$ \\
\hline \multirow[t]{2}{*}{$\begin{array}{l}\text { Patients in BICU and } \\
\text { control of infection }\end{array}$} & Huang et al. ${ }^{[9]}$ & China & A literature review. & $\begin{array}{l}\text { - Establishing venous access channels is the first level of } \\
\text { exposure to COVID-19 infection during early treatment } \\
\text { of burn patients. } \\
\text { - The establishment of endotracheal intubation or } \\
\text { tracheotomy has the higher risk of exposure. }\end{array}$ \\
\hline & Ma et al..$^{[7]}$ & China & $\begin{array}{l}\text { Recommendations/ } \\
\text { suggestions }\end{array}$ & - Central air conditioning should be avoided. \\
\hline
\end{tabular}




\section{Table I: Continued}

- $1000 \mathrm{mg} / \mathrm{L}$ chlorine-containing or $75 \%$ alcohol disinfectants are ideal for disinfecting tablets and wipe or soak disinfection.

- The floor needs $1000 \mathrm{mg} / \mathrm{L}$ chlorine-containing disinfectant to be properly wiped or sprayed with from the outside to

Treatment of burn patients with joint inhalation injury

\section{Ma et al. ${ }^{[7]} \quad$ China}

Ma et al. ${ }^{[7]}$

China

postoperative recommendations

\section{Huang et al. ${ }^{[9]}$}

China

Pre-lduring-land postoperative recommendations: Preoperative preparation

Pre-lduring-land postoperative recommendations: During the surgery
Recommendations/ suggestions

Recommendations/ suggestions

A literature review

Recommendations/ suggestions

A literature review

Recommendations/ suggestions

A literature review

Recommendations/ Suggestions

Recommendations/ suggestions

postoperative

recommendations:

Postoperative

treatment

Rehabilitation

Ma et al..$^{[7]}$

China

Recommendations/ suggestions

Li et al. ${ }^{[8]} \quad$ China
the inside, no less than half an hour each time

- Put patients with combined inhalation injury in a negative pressure quarantine room.

- All patients are guided to perform position change and coughing sputum by themselves.

- It is prohibited to inject normal saline into the endotracheal tube for lavage as it evokes intense coughing.

- Invasive operations, such as sputum absorption and airway lavage should be minimized as much as possible.

- Surgical treatments can be administrated in a timely manner based on the regular surgical procedures for patients who have been admitted to the hospital for more than 14 days and show no symptoms of COVID-I9.

- For emergency surgeries, complete lung CT and blood tests must be performed right before surgery, and COVID-19 screening should be undertaken according to clinical symptoms and epidemiology.

- Depending on the patient's situation, do or redo COVID- 19 related tests, especially lung CT scan, pharynx swab and new coronavirus nucleic acid testing.

- Surgery is the highest risk point of COVID-19 infection exposure in the early treatment of burn patients.

- For patients who are not confirmed to be negative on COVID-19 testing, emergency procedures such as general anesthesia or endotracheal intubation should be performed in the negative-pressure operating room. - The standard protection actions for operations of Class A infectious diseases must be strictly implemented by all medical workers.

- Debridement and dressing change or vacuum aspiration therapy can be carried out at phase I, while skin grafting has to be performed at phase II.

- All objects and surfaces should be disinfected and sterilized efficiently.

- Operation Room staff must not be permitted to enter the ward and should stay in the hall to take care of the patients before or after the operation.

- Disinfection of surgical tools and other medical materials and the operating room should be done firmly in accordance with the management requirements of Class A infectious diseases.

- Careful observation of the patient's situation should be paid after surgery and monitoring symptoms of respiratory infections is highly recommended.

- Suspend the rehabilitation treatment with close contact.

- Patients are advised to appropriately perform self-administered bedside rehabilitation training.

- Patients can do an online check-in and share their status and improvement of rehabilitation. 


\begin{tabular}{|c|c|c|c|c|}
\hline Scope & Study ID & $\begin{array}{l}\text { Place or } \\
\text { professional society }\end{array}$ & $\begin{array}{l}\text { Article type or study } \\
\text { design }\end{array}$ & Key points (results) \\
\hline \multirow[t]{3}{*}{ Emotional support } & Ma et al..$^{[7]}$ & China & $\begin{array}{l}\text { Recommendations/ } \\
\text { suggestions }\end{array}$ & $\begin{array}{l}\text { - Fast consultation on diseases can carried out through } \\
\text { the Internet alone, which enables patients to receive } \\
\text { professional advice without coming to a face-to-face } \\
\text { contact with a physician. }\end{array}$ \\
\hline & Ryan et al. ${ }^{[I]}$ & The US & A letter to the editor & $\begin{array}{l}\text { - Quarantine and limited ability for social interaction may } \\
\text { aggravate post-traumatic stress disorder (PTSD) and } \\
\text { depression and further hinder burn recovery. } \\
\text { - Burn survivors are prone to suffer from social seclusion } \\
\text { related to their scars, body image, and posttraumatic } \\
\text { stress symptoms. }\end{array}$ \\
\hline & Li et al. ${ }^{[8]}$ & China & $\begin{array}{l}\text { Recommendations/ } \\
\text { Suggestions }\end{array}$ & $\begin{array}{l}\text { Deliver fully consistent video chats for patients in order } \\
\text { to ease the psychological stress without compromising } \\
\text { the health of family members. }\end{array}$ \\
\hline \multirow[t]{5}{*}{$\begin{array}{l}\text { Cross-clinical aspects } \\
\mathrm{I}: \text { Pain management }\end{array}$} & Griggs et al. ${ }^{[12]}$ & The US & A literature review & $\begin{array}{l}\text { - Pain management is one of the most challenging aspects } \\
\text { in treatment of burns patients. } \\
\text { - Highly effective pain management leads to the best } \\
\text { outcomes. }\end{array}$ \\
\hline & $\begin{array}{l}\text { Cáceres-Jerez } \\
\text { et al. }{ }^{[13]}\end{array}$ & Colombia & A literature review & $\begin{array}{l}\text { - Presenting a protocol for managing of underlying pain in } \\
\text { burn patients. }\end{array}$ \\
\hline & $\begin{array}{l}\text { Sodhi and } \\
\text { Mahyar }{ }^{[14]}\end{array}$ & Canada & A commentary & $\begin{array}{l}\text { - Some recent reports have suggested that the use of } \\
\text { (NSAIDs) drugs (e.g., ibuprofen) in COVID-19 patients may } \\
\text { worsen related symptoms and increase the disease severity. }\end{array}$ \\
\hline & Robinson ${ }^{[15]}$ & England & $\begin{array}{l}\text { Summary of a literature } \\
\text { review }\end{array}$ & $\begin{array}{l}\text { - The National Health Service (NHS) in England advises } \\
\text { that patients could choose either acetaminophen or } \\
\text { ibuprofen as self-medication for COVID-19 symptoms. }\end{array}$ \\
\hline & $\begin{array}{l}\text { Shanthanna } \\
\text { et al. }{ }^{[16]}\end{array}$ & $\begin{array}{l}\text { American Society of } \\
\text { Regional Anesthesia } \\
\text { and Pain Medicine }\end{array}$ & A joint statement & $\begin{array}{l}\text { - Recommending to continue using prescribed NSAIDs on } \\
\text { a regular basis. }\end{array}$ \\
\hline
\end{tabular}

(ASRA) and European Society of Regional Anesthesia and Pain Therapy (ESRA)

The UK

A retrospective study II : Coagulopathy

\begin{tabular}{|c|c|c|}
\hline Glas et al. ${ }^{[17]}$ & The Netherlands & A literature review \\
\hline Shirol et al. ${ }^{[18]}$ & India & $\begin{array}{l}\text { A survey and a literature } \\
\text { review. }\end{array}$ \\
\hline $\begin{array}{l}\text { Connors and } \\
\text { Levy }^{[4]}\end{array}$ & The U.S & A perspective study \\
\hline
\end{tabular}

- Not recommending any changes in opioid management strategies.

- Thromboembolic complications are commonly seen in severe cases.

- Thromboembolic complications play an important role in increasing comorbidity and mortality.

- Reporting the need for increased dosage of low-weight molecular heparin (LWMH) in severe burn patients.

- Proposed therapeutic strategies for management of coagulopathy in severe burn patients are recommended.

- Recommending routine chemical venous thromboembolism (VTE) prophylaxis for burn patients with particular risk factors.

- COVID-19 associated coagulopathy is usually related to the severity of disease.

- COVID-19 patients present with notable elevations in D-dimer and fibrinogen degradation products concentration.

- The incidence of bleeding manifestations and hemorrhagic complications in COVID-19 patients is uncommon.

- Subcutaneous low molecular weight heparin should be administrated for all COVID- 19 inpatients at a standard venous thromboembolism (VTE) prophylaxis dose.

- An escalated dose VTE prophylaxis should be considered in special cases.

- Bleeding manifestations and hemorrhagic complications in COVID- 19 patients are uncommon.

- It is recommended to monitor coagulopathy by measuring D-dimer levels, PT, and platelet count every three days in severe COVID- 19 cases. 


\section{DISCUSSION}

\section{Burn management during the COVID-19 pandemic} In the following, we discuss the management of both minor and major burns during this pandemic, covering all aspects of home treatment, hospital admission, ward preparations, pre-Iduring-Ipostoperative recommendations, rehabilitation treatment, emotional support and the use of telemedicine in burn patients during COVID-19 pandemic. These suggestions are based on experiences described by burn centers sharing their strategies to deal with the COVID-19 pandemic. However, none of them provides robust clinical data that could allow us to draw evidencebased conclusions. Hence, we decided to present a synthesis of all published instructions hoping this could help other centers better cope with COVID-19 pandemic.

\section{First aid treatment for minor burns at home}

Like most clinical departments during the COVID-19 pandemic, burn departments recommend that all patients should stay home and avoid coming to any hospital unless it is an extremely critical situation. Minor burns $<10 \%$ total body surface area (TBSA) are not routinely admitted, ${ }^{[6]}$ and they can be easily managed domestically. Information about treating small-area burns should be provided for patients and their close ones. People must be advised to abide by the standard strategy of treating burns; flushing, doffing, clothing, soaking, disinfecting, and bandaging to minimize exposure. First, the burn area needs to be flushed for over 30 minutes. We consider the flushing adequate if the patient does not experience any pain upon moving away from the cold water for 25 minutes. Afterwards, a disinfectant such as iodophor can be applied over the wound area accompanied by superficial application of topical antibiotics, and the affected area needs to be bandaged. ${ }^{[7]}$

\section{Hospital admissions in general; burn patient classifications and ward management during COVID-19 pandemic}

Recently, all clinical services categorize their COVID-19realted patients in three categories: confirmed, suspected and close contact with COVID-19 patients. Ma, Yuan, Peng and colleagues from Chongquing's Institute of Burn Research suggested that burn patients who need to be hospitalized and are diagnosed with COVID-19 can be admitted in one burn department. Meanwhile, suspected patients with new coronavirus pneumonia must be immediately managed in isolation according to the same group. ${ }^{[7]}$ They also recommended admitting patients one by one, and no more than a companion should be allowed for each patient. ${ }^{[7]}$ Regarding the organization on the inside, only one caregiver is permitted to escort each mature patient and only two caregivers for pediatric ones. Changing the caregiver shall not be permitted ${ }^{[8]}$ In this Chinese hospital, preliminary screening, which includes blood routine and chest computerized tomography (CT) examinations, is
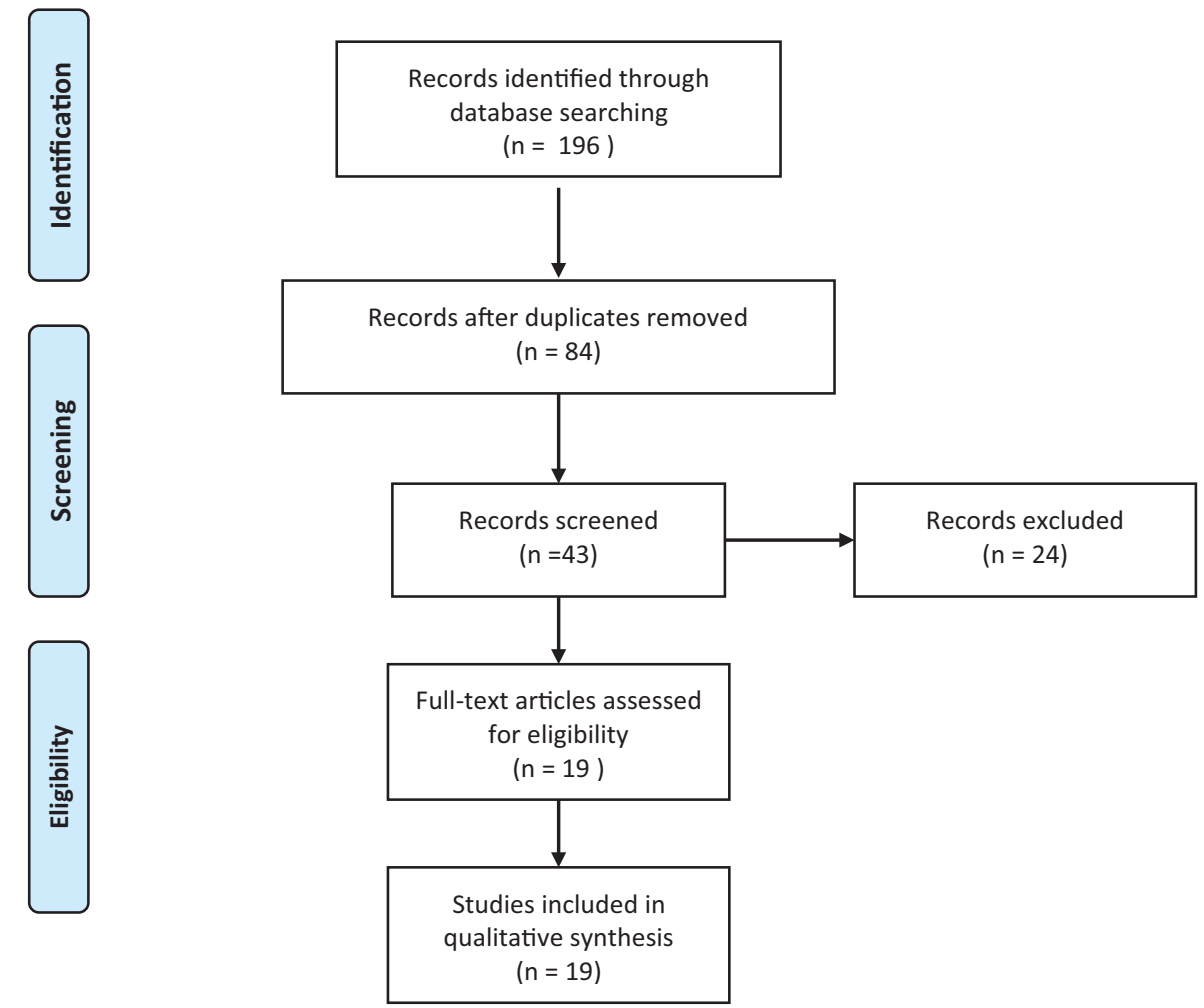

Figure 1: PRISMA 2009 flow diagram explaining the selection process 
performed routinely on all newly admitted patients. Patients with negative results in the preliminary screening can be hospitalized whereas those with lymphocyte number decline and/or exudative inflammation shown by chest CT must--if possible--go to the fever clinics, which are specialized clinics that help to assess people who may be infected with COVID-19 and to keep people who may be contagious away from other areas of hospitals, for further verification. This might help to reduce the potential spread of the virus and keep the emergency department accessible for emergencies. ${ }^{[7]}$

\section{Ward preparations}

The same group previously mentioned had set up separate areas of wards to be a short term isolation space. Every new burn patient, including pediatric ones, in this space undergo solitary isolation for 3-5 days, 14 days is recommended if possible, for medical observation. ${ }^{[7]}$ However, severe burn patients should be admitted to the burn intensive care unit (BICU) and be treated as suspects of COVID-19 with a close adherence to the recommendations of infectious disease specialists. ${ }^{[8]}$ Then, these patients can be transferred to other wards for further treatment. If patients do not present any symptoms of COVID-19 after 2 weeks, they can be accommodated. ${ }^{[7]}$ Authors also advise all related wards to be divided into a clean area, a potentially infected area and an infected area. Among these three spaces there has to be noticeable signs and instructive lines. Public spaces in the ward such as the centers of rehabilitation, wound treatment and scar management shall be available only for patients who have been admitted to the hospital for more than 2 weeks. ${ }^{[8]}$

Management of major burns

Medical history taking, and fever as a frequent clinical symptom of COVID-19 and burns

Similar to all types of clinical practice, practitioners are expected to first ask whether the patient and the companion had been to any infected area in the past 2 weeks, or whether there is a suspected history of interaction with an infected person. Then, taking the medical history related to the burn in detail as usual. Fever is common in patients with major burns. Accompanied by respiratory tract injuries, the patients' state can deteriorate. Burn patients are also prone to pulmonary edema because of systemic inflammatory response syndrome (SIRS) and over-rehydration treatment. Lungs' radio-examinations in burn patients show several small spots and interstitial infiltrations, which bare a close resemblance to the early radiological findings of COVID-19. Therefore, it is fairly difficult to tell the two conditions apart clinically. ${ }^{[9]}$ To solve such a demanding clinical issue, there is--unfortunately--no proved test so far. One could first try to approach determining the cause of fever by a detailed inquiry about the history related to exposure to the infection. Chest CT and routine blood tests could also aid in diagnosis. As a result, suspected patients should undertake the new coronavirus nucleic acid test. Major burns that cause fever have some distinctive features such as wide area burns, wounds with substantial exudate, or following major surgeries. Fever related to burn wounds is not accompanied by coughing except for cases associated with inhalation injuries. Blood tests usually indicate high white blood cell levels and elevated pro-calcitonin. A decline in neutrophil levels can be detected in some severely infected patients (with normal CT and negative test). ${ }^{[7]}$ Shortly, clinical signs, imaging, and laboratory tests can only be complementary to the clinical sense of the practitioner to distinguish burnrelated from COVID-related fever cases, in the absence of established evidence-based tests.

\section{Dressing changes for burns}

As usual, surgical gloves should be worn to provide protection; however, hand hygiene is essential before and after any interaction with the patient. If there is a possible infectious exposure during wound examination and dressing change, instantly flush with water and disinfect any area that might be infected with $75 \%$ ethanol (volume fraction) or chlorine disinfectant (effective chlorine content $500 \mathrm{mg} / \mathrm{L}$ ). Disposable surgical clothing can be worn over a white coat to enhance protection. ${ }^{[7]}$ For patients who require dressing change on a daily basis, we can extend the interval between changes depending on the exudate and the progress of the wound up to 2-3 days. In order to reduce the frequency of dressing change, exposure $\backslash$ semi-exposure therapy can be performed in some patients based on the condition of their wound. ${ }^{[7]}$ It is also recommended to take advantage of modern dressing such as foam dressing and negative pressure wound therapy (vacuum-assisted closure) to prolong the intervals and decrease frequencies of wound dressing change. ${ }^{[10]}$

\section{Patients in BICU and control of infection}

Most patients with severe burns are admitted in the BICU where procedures such as endotracheal intubation, tracheotomy, and peripheral or a central venipuncture are performed frequently. Although close contact is one of the core means of spread of COVID-19, healthcare workers need to have close contact with BICU patients regardless of the potential risk. ${ }^{[9]}$ While the process of establishing venous access channels is the first level of exposure to COVID-19 infection during early treatment of burn patients, the establishment of endotracheal intubation or tracheotomy had the uppermost risk of exposure for the COVID-19 infection. ${ }^{[9]}$ Several authors warn of the importance of disinfecting the whole department and airing 
it with the circulating air sterilizer thrice a day for more than half an hour each time. Central air conditioning should be avoided. Infrared burn treatment equipment must be used to keep patients warm and preserve adequate natural ventilation. $1000 \mathrm{mg} / \mathrm{L}$ chlorine-containing or $75 \%$ alcohol disinfectants are ideal for disinfecting tablets and wipe or soak disinfection. The floor needs $1000 \mathrm{mg} / \mathrm{L}$ chlorinecontaining disinfectant to be properly wiped or sprayed with from the outside to the inside, no less than half an hour each time. Disinfection of public air should be done when the space is vacant. Acid peroxide and hydrogen peroxide are used for extremely low capacity spray disinfection, and the disinfection process must be performed also three times a day. ${ }^{[7]}$

Treatment of burn patients with joint inhalation injury It is recommended to put patients with combined inhalation injury in a negative pressure quarantine room. All patients are guided to perform position change and coughing sputum by themselves. However, it is prohibited to inject normal saline into the endotracheal tube for lavage as it evokes intense coughing. Invasive operations, such as sputum absorption and airway lavage should be minimized as much as possible. Moreover, artificial airways are timely removed to diminish respiratory secretion splash due to open airways. ${ }^{[7]}$

Pre- \during-\and postoperative recommendations Because of the overwhelming number of elements to take into consideration during the COVID-19 crisis, the previously mentioned Chinese group recommends adopting an operative program as simple and effective as possible. This would help shorten the time of single procedures such as tracheotomy, escharotomies, debridement and skin grafting for wide area of third-degree burn wound or infective wound and debridement and coverage of necrotic tissue including blood vessels, nerves, tendons...etc. ${ }^{[7]}$ Surgical treatments can be administrated in a timely manner based on the regular surgical procedures for patients who have been admitted to the hospital for more than 14 days and show no symptoms of COVID-19. ${ }^{[7]}$ The suspected or confirmed cases of COVID-19 should apply droplet quarantine and contact isolations as well as air isolation which is essential for medical operations producing aerosols ${ }^{[8]}$ For emergency surgeries, complete lung CT and blood tests must be performed right before surgery, and COVID-19 screening should be undertaken according to clinical symptoms and epidemiology. ${ }^{[9]}$

\section{Preoperative preparation}

Depending on the patient's situation, do or redo COVID19-related tests, especially lung CT scan, pharynx swab and new coronavirus nucleic acid testing. ${ }^{[7]}$ Both close contact with patients' bodily fluids and prolonged exposure to high concentrations of aerosols in a fairly closed environment are means of transmission of COVID-19. Therefore, surgery is the highest risk point of COVID-19 infection exposure in the early treatment of burn patients. ${ }^{[9]}$ For patients who are not confirmed to be negative on COVID-19 testing, emergency procedures such as general anesthesia or endotracheal intubation should be performed in the negative-pressure operating room, and the healthcare professionals need to take tertiary precautious actions. ${ }^{[9]}$

\section{During the surgery}

- The standard protection actions for operations of Class A infectious diseases must be strictly implemented by all medical workers involved in the operation following Ma et al..$^{[7]}$ recommendations.

- Operation Room staff must not be permitted to enter the ward and should stay in the hall to take care of the patients before or after the operation. ${ }^{[8]}$

- Simple and efficient measures for the operation must be taken as the circumstance allows. For instance, debridement and dressing change or vacuum aspiration therapy can be carried out at phase I while skin grafting has to be performed at phase II. ${ }^{[7]}$

- Exposure of deep vital tissue should be avoided and the time of one operation shortened. ${ }^{[7]}$

- All objects and surfaces should be disinfected and sterilized efficiently according to the disinfection regimen according to Xiong et al. ${ }^{[9]}$

\section{Postoperative treatment}

Few authors like Ma and colleagues urge following the protocol of using antiviral drug treatment for Covid-19. In addition, disinfection of surgical tools and other medical materials and the operating rooms should be done firmly in accordance with the management requirements of Class A infectious diseases. Careful observation of the patient's situation should be paid after surgery and monitoring symptoms of respiratory infections is highly recommended as well. ${ }^{[7]}$

\section{Rehabilitation treatment and discharge}

It is advised to suspend the rehabilitation treatment with close contact. Also, evade the hazard of contact with medical workers caused by unnecessary medical activities. ${ }^{[7]}$ Patients can instead do an online check-in and share their status and improvement of rehabilitation. ${ }^{[8]}$ Whenever recovering patients need to be readmitted due to their disease situation, they can be evaluated by their examiner through an outpatient appointment system with precautionary actions ${ }^{[8]}$ Moreover, patients are advised to appropriately 
perform self-administered bedside rehabilitation training. In addition to meeting the criteria of discharge from the burn department, discharge criteria of COVID-19 must be met. In general, after discharge, patients in the key affected areas are not advised to instantly return to non-epidemic areas. $^{[7]}$

Finally, we still lack sufficient data to determine in an evidence-based manner what strategy is the best to manage burn patients while minimizing the risk of COVID-19 contamination. Experiences referenced in the previous section of the review came from several centers worldwide (Asia, America, and Europe). However, none of these publications included robust forms of data analyses hindering the classical process of building evidence in clinical medicine. While waiting for reliable retrospective analyses from burn centers, we hope that this comprehensive synthesis of few reported worldwide experiences could help others better handle the COVID-19 crisis in their centers.

\section{Emotional support and the rule of telemedicine for the treatment of burn patients during covid-19 pandemic}

Fast and precise consultation on diseases can be carried out through the Internet alone, which enables patients to receive professional advice without coming to a face-to-face contact with a physician, which minimizes the risk of infection. ${ }^{[7]}$ Quarantine and limited ability for social interaction may aggravate post-traumatic stress disorder (PTSD) and depression and further hinder burn recovery. Patients with severe burn injuries can also experience fear and anxiety due to the COVID-19 pandemic. This might cause isolation for burn patients with COVID-19 and a tough experience that requires emotional support. ${ }^{[1]}$ Many wards therefore deliver fully consistent video chats for patients to ease the psychological stress without compromising the health of family members ${ }^{[8]}$ Furthermore, burn survivors are prone to suffer from social seclusion related to their scars, body image, and depressive and posttraumatic stress symptoms. ${ }^{[11]}$

\section{Cross-clinical aspects and complications caused by both extensive burns and COVID-19 infections Pain management}

Pain management is one of the most challenging aspects in treatment of burns patients. Highly effective pain management leads to the best outcomes in burn wound healing, anxiety control and rehabilitation. ${ }^{[12]}$ These effective pain management strategies should take into consideration all of the somatic, physical, emotional, and psychosocial aspects of burn patients. ${ }^{[13]}$ The underlying pain management consists of acetaminophen as an around-the-clock (ATC) analgesic. Furthermore, a short-term use of non-steroid anti-inflammatory drugs (NSAIDs, for example, ibuprofen or diclofenac) should be considered. If pain control is not accomplished or NSAIDs are contraindicated, a weak opioid agonist (tramadol or codeine) could also be added. If all fails, a strong opioid agonist (morphine) could be administered instead. ${ }^{[13]}$

Pain management plan for COVID-19 burn patients; the efficacy and efficiency of the previously mentioned analgesics:

\section{- Acetaminophen (Tylenol)}

It is considered safe according to most health authorities. ${ }^{[1,15]}$

- NSAIDs

Some recent reports have suggested that the use of (NSAIDs) drugs (e.g., ibuprofen) in COVID-19 patients may worsen related symptoms and increase the disease severity. ${ }^{[14,16]}$ In contrary, a joint statement was published by American Society of Regional Anesthesia and Pain Medicine (ASRA) and European Society of Regional Anesthesia and Pain Therapy (ESRA)(March 27, 2020) to confirm that the evidence of this potential harm is not definitive and recommend to continue using prescribed NSAIDs on a regular basis. ${ }^{[16]}$ The statement also showed that the use of NSAIDs may cover COVID-19 symptoms, so educating patients on this entity is crucial. ${ }^{[16]}$ Moreover, the National Health Service (NHS) in England advises that patients could choose either acetaminophen or ibuprofen as selfmedication for COVID-19 symptoms. ${ }^{[15]}$

- Opioids: The previously mentioned statement has not recommended any changes in opioid management strategies; it has only emphasized on accurate monitoring for COVID-19 patients who are on opioids, especially for respiratory depression and fever. ${ }^{[16]}$

Consequently, and in the absence of trustworthy clinical trials, the therapeutic strategy for underlying pain management in COVID-19 burn patients remains similar to the regular burn patients; however, more attention for the opioid administration should be paid.

\section{Coagulopathy}

In Burn Patients, thromboembolic complications are commonly seen in severe cases. They play an important role in increasing comorbidity and mortality (responsible for more than $3 \%$ of all deaths after burn injuries). ${ }^{[3,17]}$ The accurate pathophysiology is still unclear, but at least, in part, the activation of the coagulopathy may be a consequence of a mixture or one of the following mechanisms: tissue 
hypo-perfusion and the resultant acidemia, burn wound excision, SIRS, the endothelial damage following the burn, sepsis, hemodilution, and hypothermia. ${ }^{[17]}$ Unfortunately, we still lack well-defined recommendations for management of coagulopathy in severe burn patients. The proposed therapeutic strategies involve general supportive methods which focus on the extenuation of triggering factors. For example, body temperature must be properly controlled, especially during fluid resuscitation period. Moreover, we need to strictly manage burn-related shock to avoid tissue hypoperfusion by sustaining a standard cardiac output along with sufficient blood pressure. Blood product transfusions are also proposed but with specific considerations. ${ }^{[17]}$

Anticoagulant strategies using activated protein C (APC), tissue factor pathway inhibitor (TFPI), anti-thrombin, and heparin have shown variable and controversial clinical efficacy. ${ }^{[17]}$ The American College of Chest Physicians (AACP) considers low-molecular-weight heparin (LMWH), for example, enoxaparin as the drug of choice. However, ACCP Guidelines (2008) recommends routine chemical venous thromboembolism (VTE) prophylaxis for burn patients with particular risk factors such as old age, lower limb burns, drawn-out immobilization, associated trauma, femoral central venous catheterization and unhealthy obesity. ${ }^{[18]}$ Moreover, Blake et al. ${ }^{[3]}$ have reported the need for increased dosage of LWMH in severe burn patients.

In critically ill patients, infectious complications usually participate in activating profound inflammatory responses and systemic coagulation. These responses are crucial for host defense; however, they can lead to thromboembolic complications. ${ }^{[4]}$ COVID-19 associated coagulopathy is usually related to the severity of disease. It is caused by thrombo-inflammation, not the intrinsic viral activity itself. ${ }^{[4]}$ COVID-19 patients present with notable elevations in D-dimer and fibrinogen degradation products concentration, while changes in prothrombin time (PT), partial thromboplastin (PTT) and platelets may not be detectible in the initial presentation. ${ }^{[4]}$ It is remarkable that the incidence of bleeding manifestations and hemorrhagic complications in COVID-19 patients is uncommon. ${ }^{[4,19]}$ It is recommended to monitor coagulopathy by measuring D-dimer levels, PT, and platelet count every three days in severe COVID-19 cases. $^{\left[{ }^{[19]}\right.}$

In general, subcutaneous low molecular weight heparin should be administrated for all COVID-19 inpatients at a standard venous thromboembolism (VTE) prophylaxis dose. ${ }^{[4]}$ Although there is no firm evidence to justify the use of an increasing dose of anticoagulants in ward patients for prophylaxis, expect for patients with morbid obesity, ${ }^{[4]}$ many doctors agreed with this dose increasing. ${ }^{[4]}$ In addition, an escalated dose VTE prophylaxis should be considered in cases like intensive care unit (ICU) and acute respiratory distress syndrome (ARDS) patients. ${ }^{[4]}$ Therapeutic dose of anticoagulation should be taken into consideration in case of confirmed VTE and presumed pulmonary embolism (PE). ${ }^{[4]}$

To sum up, it is notable that coagulopathy occurs in both burn and COVID-19 patients and may lead to serious complications. For this, burn patients associated with COVID-19 require strict monitoring and followup. Routine chemical VTE prophylaxis should be also applied. An escalated dose VTE prophylaxis should be seriously considered as the risk of coagulopathy notably increases in such cases. On a final note, we do emphasize the importance of conducting randomized controlled trials in order to establish robust guidelines for the management of coagulopathy in COVID-19 patients with major burns.

\section{CONCLUSION}

Owing to the high risk of contamination for both burn patients and caregivers, it seems essential to follow strict strategies of management in each burn center aiming to control the spread of COVID-19. In general, these strategies should focus on educating people on first aid treatment for minor burns to reduce the exposure of individuals to the hospital environment, and guiding physicians to achieve the optimal management for burn inpatients during this pandemic. Hospitalization of burn patients, regardless of the burn degree, can be severely impacted by the pandemic control measures. Therefore, burn centers ought to find an effective balance between providing the best care possible for their patients and limiting the spread of COVID-19. This balance can prove difficult to achieve especially in medically poor environments. Few burn centers around the globe had published reasonable recommendations to handle the crisis. In short, these recommendations consist of limiting contact as much as possible, meeting high hygiene standards, isolating potentially contaminated patients when possible, and following efficient and shorter care programs. Although these recommendations are based on mere experiences, they are all what the literature can currently offer to health care professionals in the burns field. Particular attention should be paid when dealing with pain management and coagulopathy in burn patients infected with COVID-19. Finally, we strongly urge the medical community to dedicate -as much as possible- human and material resources for real-time clinical research in burn centers to allow the establishment of reliable strategies for burn management during the COVID-19 pandemic. This 
would not only help managing the current crisis, but also other airborne pandemics possibly happening in the future.

\section{Acknowledgement}

All thanks go to Zeinab Mohanna, an English literature student in Tishreen University, for her linguistic revision.

\section{Financial support and sponsorship}

Nil.

\section{Conflicts of interest}

There are no conflicts of interest.

\section{REFERENCES}

1. WHO Coronavirus Disease (COVID-19) Dashboard. Available from: https://covid19.who.int/. [2020 Jun 11, 2:20 PM CEST].

2. WHO: Fact Sheets on Burns. Available from: https://www.who.int/en/ news-room/fact-sheets/detail/burns.

3. Blake M, Roadley-Battin R, Torlinski T. Prophylactic anti-coagulation after severe burn injury in critical care settings. Acta Med Litu 2019;26:38-45.

4. Connors JM, Levy JH. COVID-19 and its implications for thrombosis and anticoagulation. Blood 2020;135:2033-40.

5. Moher D, Liberati A, Tetzlaff J, Altman DG; PRISMA Group. Preferred reporting items for systematic reviews and meta-analyses: The PRISMA statement. Ann Intern Med 2009;151:264-9, W64.

6. Barret JP, Chong SJ, Depetris N, Fisher MD, Luo G, Moiemen, et al. Burn center function during the COVID-19 pandemic: An international multicenter report of strategy and experience. Burns 2020;46:1021-35.

7. Ma S, Yuan Z, Peng Y, Chen J, Li H, Luo Q, et al. Experience and suggestion of medical practices for burns during the outbreak of COVID-19. Burns 2020;46:749-55.

8. Li N, Liu T, Chen H, Liao J, Li H, Luo Q, et al. Management strategies for the burn ward during COVID-19 pandemic. Burns 2020;46:756-61.
9. Huang Z, Zhuang D, Xiong B, Deng DX, Li H, Lai W. Occupational exposure to SARS-CoV-2 in burns treatment during the COVID-19 epidemic: Specific diagnosis and treatment protocol. Biomed Pharmacother 2020;127:110176.

10. Wang R, Peng Y, Jiang Y, Gu J. Managing chronic wounds during novel coronavirus pneumonia outbreak. Burn Trauma 2020;8:4-7.

11. Ryan CM, Stoddard FJ, Kazis LE, Schneider JC. COVID-19 pandemic and the burn survivor community: A call for action. Burns 2020. doi: 10.1016/j.burns.2020.04.018. [published online ahead of print, 2020 Apr 24].

12. Griggs $C$, Goverman J, Bittner EA, Levi B. Sedation and pain management in burn patients. Clin Plast Surg 2017;44:535-40.

13. Cáceres-Jerez LE, Gomezese-Ribero OF, Reyes-Cárdenas LI, et al. Manejo del dolor agudo en el paciente gran quemado: Revisión no sistemática de la literatura TT - Management of acute pain in extensive burn injury: Nonsystematic review of the literature. Rev Colomb Anestesiol 2018;46:49-54.

14. SodhiM, Mahyar E. Safety of Ibuprofen in patients with COVID-19: Causal or confounded?. Chest 2020;158:55-6.

15. Robinson J. Paracetamol or ibuprofen can be used to treat the symptoms of COVID-19, says NHS England. Pharma J 2020. Available from: https://www.pharmaceutical-journal.com/news-and-analysis/ news/paracetamol-or-ibuprofen-can-be-used-to-treat-the-symptomsof-covid-19-says-nhs-england/20207906.article?firstPass=false.

16. Shanthanna H, Cohen SP, Strand N, Eldabe S, Bhatia A, Narouze S. Recommendations on Chronic Pain Practice during the COVID-19 Pandemic. In: ASRA/ESRA COVID-19 Guidance for Chronic Pain Practice 2020. Available from: https://www.asra.com/page/2903/ recommendations-on-chronic-pain-practice-during-the-covid-19pandemic.

17. Glas GJ, Levi M, Schultz MJ. Coagulopathy and its management in patients with severe burns. J Thromb Haemost 2016;14:865-74.

18. Shirol SS, Kodaganur S, Rao MR, Tiwari V. The conundrum of deep vein thrombosis prophylaxis in burns in india and review of literature. Indian J Plast Surg 2017;50:288-94.

19. Levi M, Thachil J, Iba T, Levy JH. Coagulation abnormalities and thrombosis in patients with COVID-19. Lancet Haematol 2020;2019:2019-21. 